\title{
Cytokeratins mediate epithelial innate defense through their antimicrobial properties
}

\author{
Connie Tam, ${ }^{1}$ James J. Mun, ${ }^{1}$ David J. Evans, ${ }^{1,2}$ and Suzanne M.J. Fleiszig1,3 \\ ${ }^{1}$ School of Optometry, University of California, Berkeley, Berkeley, California, USA. ${ }^{2}$ College of Pharmacy, Touro University California, Vallejo, California, USA. \\ ${ }^{3}$ Programs in Vision Science, Infectious Disease and Immunity, and Microbiology, University of California, Berkeley, Berkeley, California, USA.
}

\begin{abstract}
Epithelial cells express antimicrobial proteins in response to invading pathogens, although little is known regarding epithelial defense mechanisms during healthy conditions. Here we report that epithelial cytokeratins have innate defense properties because they constitutively produce cytoprotective antimicrobial peptides. Glycine-rich C-terminal fragments derived from human cytokeratin $6 \mathrm{~A}$ were identified in bactericidal lysate fractions of human corneal epithelial cells. Structural analysis revealed that these keratin-derived antimicrobial peptides (KDAMPs) exhibited coil structures with low $\alpha$-helical content. Synthetic analogs of these KDAMPS showed rapid bactericidal activity against multiple pathogens and protected epithelial cells against bacterial virulence mechanisms, while a scrambled peptide showed no bactericidal activity. However, the bactericidal activity of a specific KDAMP was somewhat reduced by glycine-alanine substitutions. KDAMP activity involved bacterial binding and permeabilization, but the activity was unaffected by peptide charge or physiological salt concentration. Knockdown of cytokeratin 6A markedly reduced the bactericidal activity of epithelial cell lysates in vitro and increased the susceptibility of murine corneas to bacterial adherence in vivo. These data suggest that epithelial cytokeratins function as endogenous antimicrobial peptides in the host defense against infection and that keratin-derived antimicrobials may serve as effective therapeutic agents.
\end{abstract}

\section{Introduction}

Exposed tissue surfaces, including skin and the mucosa, are under constant threat of attack by opportunistic and pathogenic microorganisms. Multilayers of epithelial cells lining this host-microbial interface form a defense barrier to prevent microbe penetration (1). Significant effort has been focused on understanding how epithelial cells participate in inflammatory responses when infectious disease occurs or during other forms of tissue challenge (2). It has been shown that Toll-like and Nod-like receptor-mediated innate defense systems allow epithelial detection of extracellular or intracellular microbes via conserved antigens, with resultant expression of cytokines and chemotactic signaling to recruit and activate cellular immune defenses (3-7). Less is known about how epithelia resist infection during health, i.e., under "constitutive" circumstances, except that they provide a formidable barrier.

As an example, the healthy human cornea resists epithelial penetration by virtually all microbes, and infection requires significant (deep-penetrating) damage or contact lens wear $(8,9)$. In animal models, even large inocula of potentially pathogenic bacteria are rapidly cleared from the ocular surface when it is healthy (10-12). Various antimicrobial peptides are expressed at ocular, and other, surfaces of humans and animals. While some (e.g., hBD-1) are constitutively expressed, many, including most $\beta$-defensins (hBD-2, $\mathrm{hBD}-3$, and hBD-4) and cathelicidin LL-37, require the activation of innate defense responses for expression and secretion $(13,14)$.

Here we tested the hypothesis that human corneal epithelial cells contained undiscovered antimicrobials that were expressed constitutively and involved in defense against infection. System-

Conflict of interest: The authors are listed as coinventors on a US Provisional Patent Application filed April 27, 2011, No. 61/479,507, and a subsequent US Patent Application submitted April, 2012, both entitled "Antimicrobial Peptides and Methods of Use Thereof," that include data presented in this article.

Citation for this article: J Clin Invest. 2012;122(10):3665-3677. doi:10.1172/JCI64416 atic fractionation of these cells, combined with mass spectrometry, revealed a series of glycine-rich C-terminal peptides of human cytokeratin 6A (hK6A) (13- to 26-amino acids). Synthetic analogs of the naturally occurring peptides were bactericidal against multiple bacterial pathogens and cytoprotective against Pseudomonas aeruginosa. Accordingly, knockdown of cytokeratin 6A (K6A) significantly reduced bactericidal activity of corneal epithelial cell lysates, and it increased bacterial adherence to the murine ocular surface. Structure-activity studies showed that glycine residues were required for activity and that the mechanism involved direct binding to bacteria and cell wall/membrane permeabilization. We believe that these data suggest a novel function for keratin proteins in innate defense against bacterial challenge.

\section{Results}

K6A contributes to the endogenous antimicrobial activity of corneal epithelial cells. A telomerase-immortalized human corneal epithelial (hTCEpi) cell line, capable of differentiation, stratification, and desquamation similar to normal epithelium (15), was used to mine for constitutively expressed antimicrobial peptides. Calcium-induced differentiated cells were lysed and fractionated by molecular weight, and fractions were screened for bactericidal activity against Pseudomonas aeruginosa, a common Gram-negative opportunistic pathogen. For the laboratory isolate PAC1R, lysate fractions containing molecules of less than $3 \mathrm{kDa}$ were most effective in killing bacteria (Figure 1A). For clinical isolates 6294 and 6206, both the $<3-\mathrm{kDa}$ and the 3- to $10-\mathrm{kDa}$ fractions were found to be bactericidal in a concentration-dependent manner (Figure 1, B and C).

To examine the functional significance of antimicrobial activity in epithelial cell lysates, lysate fractions were tested for their capacity to impact virulence mechanisms of $P$. aeruginosa. Both the $<3-\mathrm{kDa}$ and the 3- to $10-\mathrm{kDa}$ small-molecule lysate fractions protected cultured human corneal epithelial cells against invasion by $P$. aeruginosa in vitro, again in a concentration-dependent manner 
A
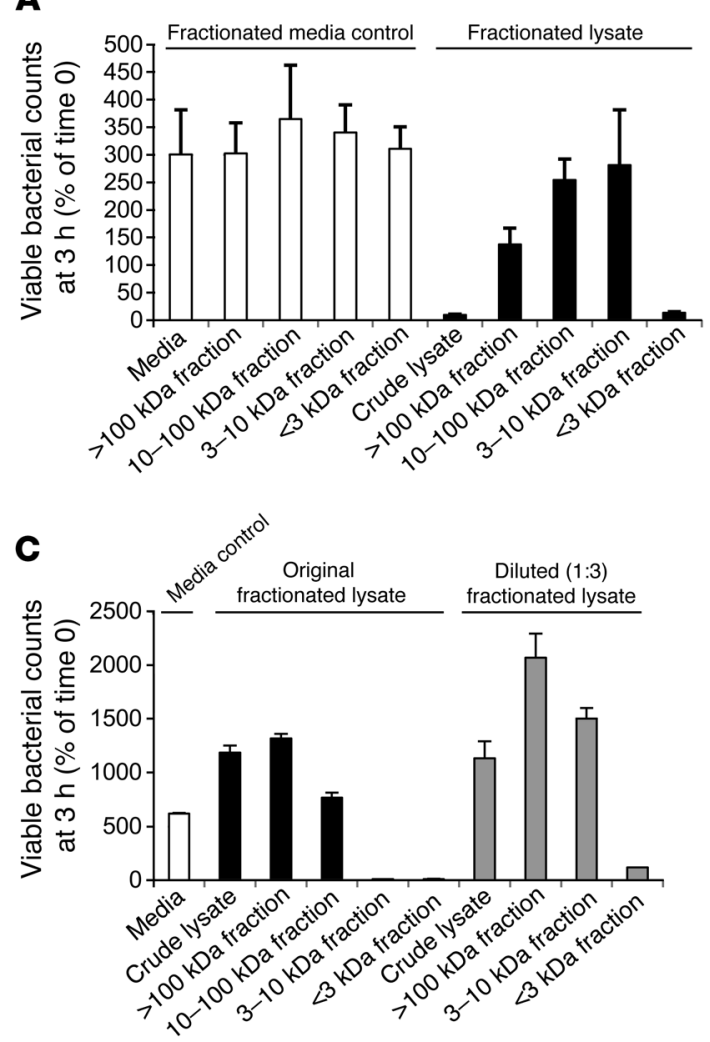

E

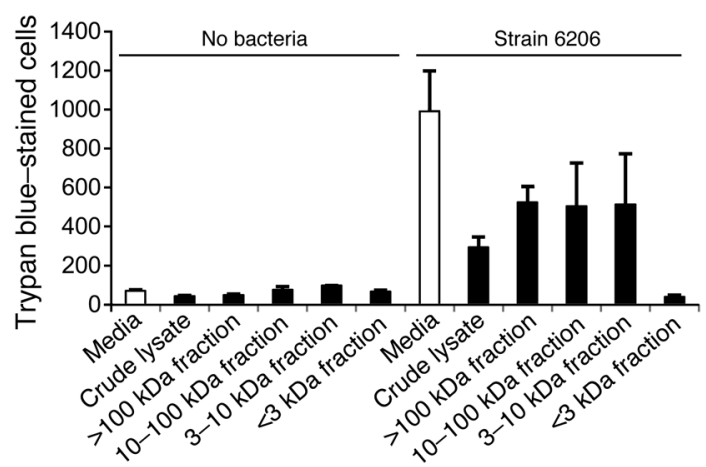

B

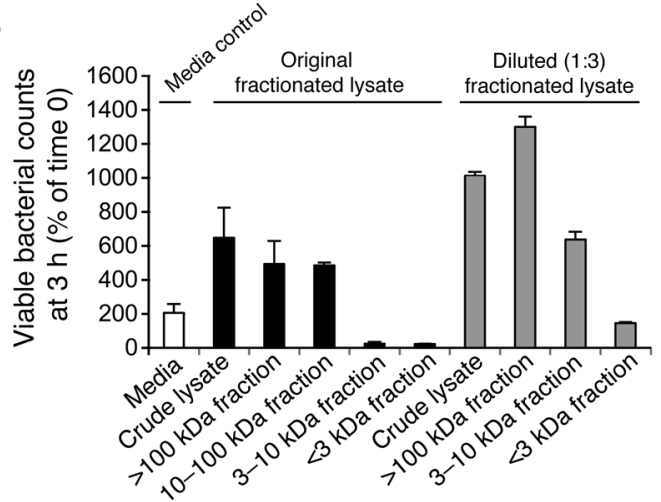

D

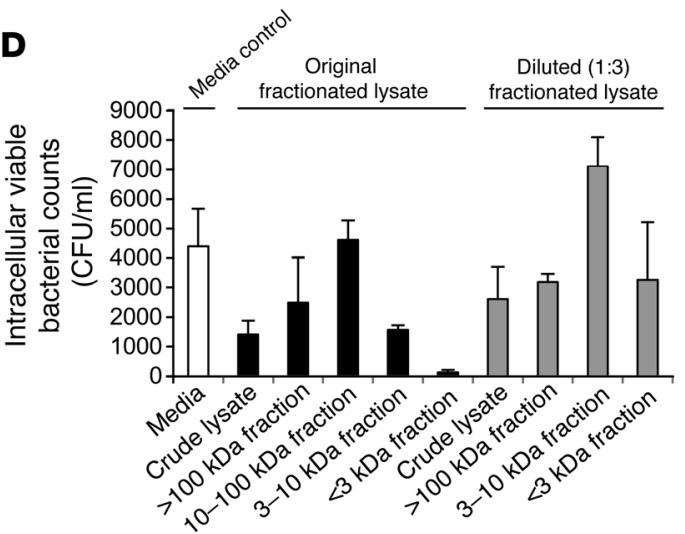

Figure 1

Keratin peptide derivatives are major constituents of the antimicrobial fractions of human corneal epithelial cell lysates. (A) Crude lysates were serially fractionated by size to yield 4 fractions: $>100 \mathrm{kDa}, 10-100 \mathrm{kDa}, 3-10 \mathrm{kDa}$, and $<3 \mathrm{kDa}$ (black). Crude lysates and the small-molecule $<3-\mathrm{kDa}$ lysate fraction showed bactericidal activity against $P$. aeruginosa (strain PAC1R). Culture media was fractionated in parallel to serve as controls for the corresponding lysate fractions in the bacterial killing assays (white). (B and C) Similar results were observed for $P$. aeruginosa clinical isolate (B) 6294 (invasive strain) and (C) 6206 (cytotoxic strain) except that 3- to 10-kDa lysate fractions were also found to be bactericidal. Dilution (1:3) (gray) reduced activity, demonstrating that antimicrobial activity was concentration dependent. (D) The $<3-\mathrm{kDa}$ and $3-$ to $10-\mathrm{kDa}$ fractions both protected epithelial cells against $P$. aeruginosa internalization. (E) The $<3-\mathrm{kDa}$ fraction protected epithelia from bacterial-induced cell death (indicated by trypan blue-staining).

(Figure 1D). The $<3-\mathrm{kDa}$ fraction also protected cells against the cytotoxic activity of P. aeruginosa strain 6206 (Figure 1E).

Since previously identified endogenously expressed antimicrobial peptides are mostly approximately 3 to $10 \mathrm{kDa}$ or larger in size (16), the bactericidal and cytoprotective activity of the $<3-\mathrm{kDa}$ fraction suggested the presence of novel antimicrobials. Thus, lysate fractions were analyzed for their peptide content using LC MS/MS (Table 1). To identify native peptides in the $<3-\mathrm{kDa}$ frac- tion, a nontrypsin-digested fraction was initially analyzed. The majority of detected fragments were derivatives of human keratins, including K5, K6A, K15, and K19. Among these, a 17-amino acid K6A peptide fragment (AIGGGLSSVGGGSSTIK, aa 534-550) was consistently detected, with or without trypsin processing (Supplemental Table 1; supplemental material available online with this article; doi:10.1172/JCI64416DS1). Interestingly, both the $\mathrm{N}$ and $\mathrm{C}$ termini of this fragment (Ala and Lys, respectively) were flanked 


\section{Table 1}

Mass spectrometric analysis of small-molecule cell lysate fractions

\begin{tabular}{lccccccc}
\hline $\begin{array}{l}\text { Lysate } \\
\text { fraction }\end{array}$ & $\begin{array}{c}\text { Tryptic } \\
\text { digestion }\end{array}$ & $\begin{array}{c}\text { Total no. } \\
\text { of proteins } \\
\text { detected }\end{array}$ & $\begin{array}{c}\text { No. of keratin } \\
\text { proteins } \\
\text { detected }\end{array}$ & $\begin{array}{c}\text { Identity of } \\
\text { detected } \\
\text { keratins }\end{array}$ & $\begin{array}{c}\text { Total no. of } \\
\text { peptides } \\
\text { detected }\end{array}$ & $\begin{array}{c}\text { No. of K6A- } \\
\text { derived peptides } \\
\text { detected }\end{array}$ & $\begin{array}{c}\text { No. of K6A } \\
\text { (aa 515-559) } \\
\text { peptides detected }\end{array}$ \\
$<3 \mathrm{kDa}$ & No & 8 & 4 & $5,6 \mathrm{~A}, 15,19$ & 9 & 2 & 2 \\
$<3 \mathrm{kDa}$ & Yes & 1 & 1 & $6 \mathrm{~A}$ & 82 & 1 & 24 \\
$3-10 \mathrm{kDa}$ & Yes & 16 & 5 & $5,6 \mathrm{~A}, 14,15,19$ & 20 & 2 \\
\hline
\end{tabular}

Mass spectrometric analysis of <3-kDa and 3- to 10-kDa lysate fractions revealed that the majority of detected peptides were keratin-derived, while K6A was common to all samples.

by a theoretical trypsin cleavage site (Arg-Ala and Lys-Tyr, respectively), suggesting that this fragment could be proteolytically released from full-length $\mathrm{K} 6 \mathrm{~A}$, e.g., via endogenous trypsin-like serine proteases. The same 17 -mer fragment was detected in the 3 - to $10-\mathrm{kDa}$ fraction, along with a series of overlapping peptides comprising its full or partial sequence (variants) derived from the C-terminal region (aa 515-559) of K6A. Together these peptides represented the majority of detected fragments in this fraction (Supplemental Table 2).

$K 6$ A contributes to ocular defense against $P$. aeruginosa in vivo. Consistent with a previous proteome study of the healthy human cornea (17), Western immunoblot confirmed the presence of full-length $(\sim 60 \mathrm{kDa})$ and fragmented $\mathrm{K} 6 \mathrm{~A}(\leq 1.7 \mathrm{kDa})$ in the crude lysate of these immortalized human corneal epithelial cells (Figure 2A). Interestingly, fragments of K6A were not observed in lysates of cells grown in KGM-2 containing lower calcium $\left(0.15 \mathrm{mM} \mathrm{CaCl}_{2}\right)$ (Figure 2A). The knockdown of hK6A expression using siRNA resulted in an increase of $P$. aeruginosa growth in the crude lysate, suggesting reduced bactericidal activity (Figure 2B). Controls showed that hK6A knockdown did not significantly impact cell density, morphology, or viability, as demonstrated by trypan blue exclusion assays (data not shown). In vivo knockdown of endogenous $\mathrm{K} 6 \mathrm{~A}$ in murine corneas (murine K6A) by approximately $25 \%$ (assessed by quantitative real-time PCR) using subconjunctival injection of siRNA was found to increase $P$. aeruginosa adherence to the surface of intact corneas ex vivo by approximately 5 fold (Figure 2, C and E). Controls revealed that this knockdown did not impact general barrier function, as indicated by the absence of penetration by fluorescein (Figure 2D). Collectively these data support the hypothesis that endogenous K6A and keratin-derived antimicrobial peptides (KDAMPs) serve an antimicrobial role in epithelial innate defense.

Structural analysis of KDAMPs. ExPASy proteomic tools were used to predict peptide secondary structures, transmembrane helices, amphipathicity (hydrophobic moment), and net charges (18-21) for 8 variants of K6A (Table 2). Notably, none of the peptides tested showed sequence homology with any known mammalian antimicrobial peptides (22), but they all exhibited a predominance of glycine repeats and a common sequence, GGLSSVGGGS. Variants of the originally identified 17 -mer fragment with an additional N- and/or C-terminal residue(s) (19-mer and two 18-mer peptides) were predicted to be favorable for antimicrobial activity based on predicted coil structure, potential for transmembrane helices, a hydrophobic face, and cationic charge. For example, the 19-mer peptide (aa 533-551) was predicted to have features associated with other well-recognized antimicrobial peptides, including a positive net charge and a coil structure able to form transmem- brane helices. In contrast, other active KDAMPs showed variability in each of these properties except predicted coil structure. A scrambled (inactive) control of the 19-mer peptide was predicted to retain similar properties to the 19-mer, e.g., positive net charge and coil structure, but not transmembrane helix formation. The scrambled 19-mer peptide also had a lower hydrophobic moment than the active 19-mer and other active KDAMPs (Table 2).

Antipsendomonal activity of synthetic KDAMPs. The bactericidal activity of synthetic K6A fragments was tested using a physiological salt $(\mathrm{NaCl})$ concentration $(150 \mathrm{mM})$ and a "lawn"/biofilmlike culture of bacteria. These conditions are known to reduce the activity of known cationic antimicrobial peptides, such as human $\beta$-defensins- $1,-2$, and -4 and cathelicidin LL-37 $(23,24)$. The 19-mer KDAMP was almost equally effective in killing the cytotoxic $P$. aeruginosa clinical isolate 6206 in $150 \mathrm{mM} \mathrm{NaCl}$ solution or in water, in both cases reducing bacterial viable counts by approximately 3 to $4 \operatorname{logs}$ after 3 hours at $200 \mu \mathrm{g} / \mathrm{ml}(P<0.005$ in each instance) (Figure 3A). This 19-mer peptide also showed bactericidal activity against the invasive clinical isolate 6294 in physiological saline, a $97.5 \%$ reduction in bacterial viability after 3 hours at $200 \mu \mathrm{g} / \mathrm{ml}$, and against a laboratory isolate PAO1, a 96.1\% reduction in viability under the same conditions $(P<0.005$ in each instance) (Figure 3B). A scrambled sequence control of the 19-mer KDAMP (IRGSVTISGYSGGLKGSAG) showed little or no bactericidal activity against all $5 P$. aeruginosa isolates tested compared with that of the natural peptide sequence $(P<0.01)$ (Figure 3C). Real-time video phase-contrast microscopy revealed that 19 -mer KDAMP-treated P. aeruginosa strain 6206 lost capacity for swimming motility and some appeared to aggregate, compared with untreated bacteria or bacteria treated with a scrambled peptide control (100 $\mu \mathrm{g} / \mathrm{ml}, 15$ minutes), in the presence of hTCEpi cells, which appeared healthy (Supplemental Videos 1-3).

Treatment of cultured human corneal epithelial cells with the 19-mer KDAMP $(200 \mu \mathrm{g} / \mathrm{ml})$ during challenge with $P$. aeruginosa protected the epithelial cells against bacterial invasion and bacteria-induced cytotoxicity as compared with controls. Bacterial invasion was reduced by $89.1 \%$, while cytotoxicity was reduced by $85.1 \%$ $(P<0.001$ in each instance) (Figure 3, D and E). Epithelial cells were not visibly impacted by peptide treatment alone, since they showed normal morphology and excluded trypan blue, which only enters epithelial cells if their membrane is permeabilized (data not shown). These data show that KDAMPs have potential to protect epithelial cells against bacterial virulence mechanisms at concentrations not toxic to host cells.

Synthetic analogs of other K6A-derived peptides detected in corneal epithelial cell lysates were also found to be active against $P$. aeruginosa strain 6206. The 18 -mer N-terminal fragment (18- 
A
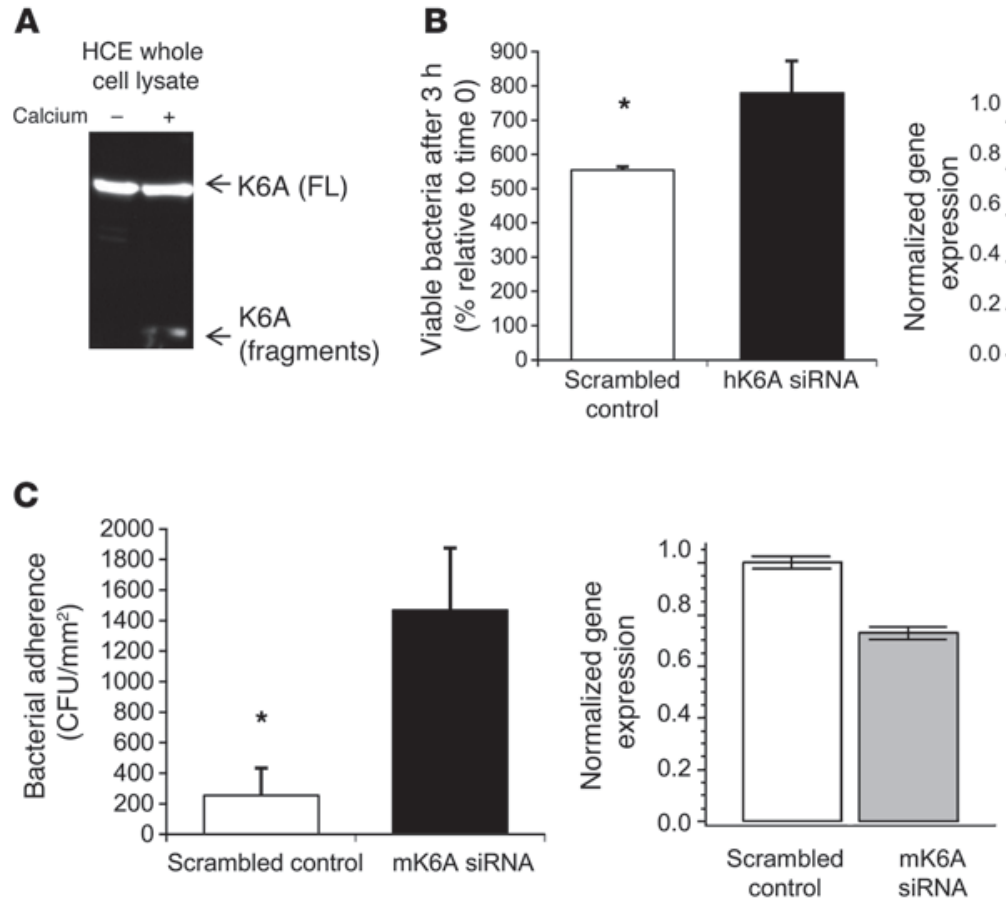

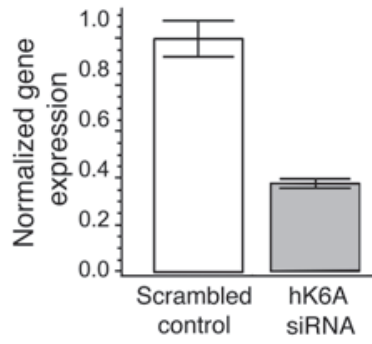

D
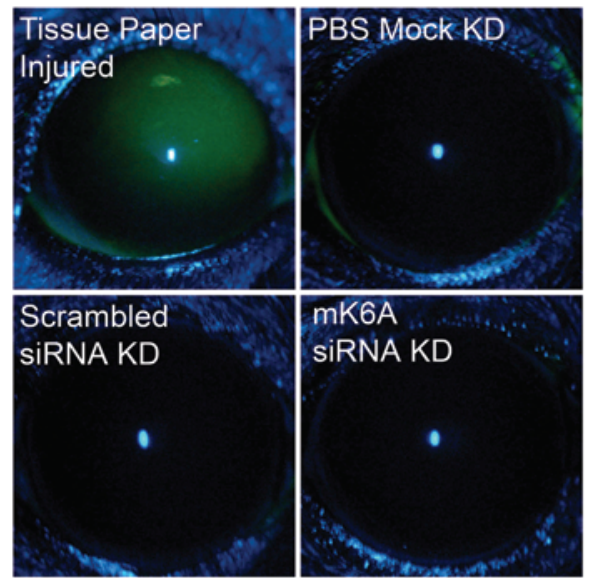

E
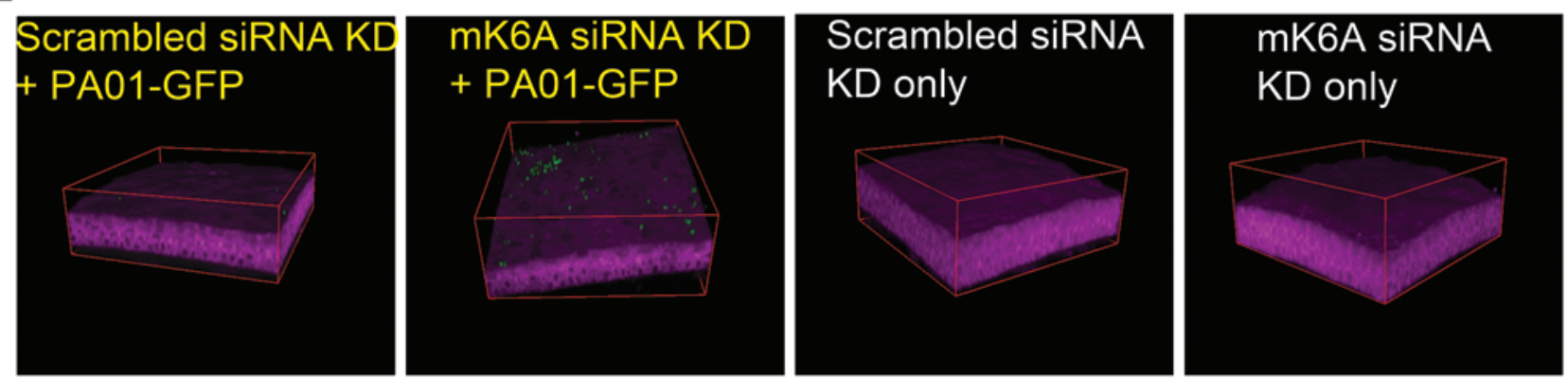

Figure 2

K6A contributes to endogenous antimicrobial activity of corneal epithelial cells. (A) Western blot of whole cell lysates (from direct lysis with SDS) confirmed constitutive expression of $\mathrm{K} 6 \mathrm{~A}$ and its fragments $(<2 \mathrm{kDa})$ in high-calcium-treated $(1.15 \mathrm{mM} \mathrm{CaCl})$ human corneal epithelial $(\mathrm{HCE})$ cells. Fragments of K6A were not observed in lysates of cells grown in $\mathrm{KGM}-2$ with lower calcium $(0.15 \mathrm{mM} \mathrm{CaCl}$ ). $\mathrm{FL}$, full length. (B) Antimicrobial activity of crude cell lysates against $P$. aeruginosa strain 6206 was attenuated by siRNA knockdown of hK6A in vitro. Knockdown efficiency was confirmed by qRT-PCR. ${ }^{*} P=0.007$. (C) Ex vivo bacterial adherence on the corneal epithelium of intact mouse eyeballs (3-hour incubation with $10^{11} \mathrm{CFU} / \mathrm{ml}$ of $P$. aeruginosa strain PAO1-GFP) was increased significantly by in vivo knockdown of mouse K6A (mK6A) in the corneas. Knockdown efficiency was confirmed by qRT-PCR. ${ }^{*} P=0.0005$. (D) Slit-lamp examination of mouse eyes showed that integrity of the physical barrier was not impacted by K6A knockdown, as indicated by the absence of corneal staining with fluorescein. A superficially injured (by tissue paper blotting) mouse cornea served as the positive control of fluorescein staining. (E) Combined 2-photon confocal imaging showed increased adherence of $P$. aeruginosa (PAO1-GFP, green) to whole corneas previously treated with siRNA for murine K6A compared with those treated with scrambled control. Without $P$. aeruginosa, siRNA treatments alone did not visibly affect corneal morphology. $Z$ stacks of $1.0-\mu \mathrm{m}$ step size $(100-\mu \mathrm{m}$ total thickness) were taken with a $\times 60$ water-dipping lens to give an $x y$ field of $210 \mu \mathrm{m} \times 210 \mu \mathrm{m}$.

mer-N), 18-mer C-terminal fragment (18-mer-C), 17-mer, 14-mer, and 13-mer (fragments within the 19-mer) each showed concentration-dependent bactericidal activity $(90 \%$ or greater killing at $200 \mu \mathrm{g} / \mathrm{ml}, P<0.0005)$ comparable to that of the 19-mer peptide (Figure 3F). Lower concentrations $(100 \mu \mathrm{g} / \mathrm{ml})$ reduced bactericidal efficacy for most KDAMPs except the 18-mer-N and the 14-mer.
These results were somewhat surprising, since several of these peptides (e.g., 14-mer and 13-mer) had predicted features less favorable for antimicrobial function, including less or no positive charge, no transmembrane helix, or hydrophobic face. However, other examples exist of truncated antimicrobial peptides retaining activity, including some of the defensins and LL-37 $(25,26)$. Two other vari- 
Table 2

Sequence and predicted structural characteristics of K6A-derived peptides

\begin{tabular}{|c|c|c|c|c|c|c|c|}
\hline Peptide & Sequence & $\begin{array}{c}\text { Predicted } \\
\text { secondary } \\
\text { structure }\end{array}$ & $\begin{array}{c}\text { Possible } \\
\text { transmembrane } \\
\text { helix }\end{array}$ & $\begin{array}{l}\text { Predicted } \\
\text { hydrophobic } \\
\text { face }\end{array}$ & pl & $\begin{array}{c}\text { Net charge } \\
(\mathrm{pH} 7.0)\end{array}$ & $\begin{array}{c}\text { Hydrophobic } \\
\text { moment } \\
(\mu \mathrm{H})\end{array}$ \\
\hline 19-mer & RAIGGGLSSVGGGSSTIKY & Coil & Yes & Yes & 9.99 & +2 & 0.279 \\
\hline 18-mer-N & AIGGGLSSVGGGSSTIKY & Coil & Yes & Yes & 8.63 & +1 & 0.238 \\
\hline 18-mer-C & RAIGGGLSSVGGGSSTIK & Coil & Yes & Yes & 11.0 & +2 & 0.348 \\
\hline 17-mer & AIGGGLSSVGGGSSTIK & Coil & Yes & No & 8.80 & +1 & 0.309 \\
\hline 14-mer & GGLSSVGGGSSTIK & Coil & No & No & 8.75 & +1 & 0.252 \\
\hline 13-mer & AIGGLSSVGGGS & Coil & No & No & 5.57 & 0 & 0.325 \\
\hline 36-mer & GLGVGGGFSSSSGRAIGGGLSSVGGGSSTIKY & Coil & Yes & No & 9.70 & +2 & 0.219 \\
\hline 10-mer & GGLSSVGGGS & Coil & No & No & 5.52 & 0 & 0.255 \\
\hline Scrambled 19-mer & IRGSVTISGYSGGLKGSAG & Coil & No & Yes & 9.99 & +2 & 0.138 \\
\hline
\end{tabular}

A 19-amino acid peptide (aa 533-551) encompassing all 5 fragments (i.e., 18-mer-N, aa 534-551; 18-mer-C, aa 533-550; 17-mer, aa 534-550; 14-mer, aa 537-550; 13-mer, aa 534-546) was predicted to be a cationic peptide. A 36-amino acid variant representing a combined sequence of 2 detected fragments (aa 517-533 and aa 534-552) parted by a tryptic cut site, a 10-amino acid variant representing the overlapping region between 14-mer and 13-mer, and an inactive scrambled 19-mer were also assessed. The shared glycine-rich sequence is underlined. pl, isoelectric point.

ants of the 19-mer with longer or shorter peptide sequences were tested: a 36-mer, comprising all previously tested variants, and a 10-mer, a sequence contained within both the 14-mer and 13-mer KDAMPs (Table 2). Both of these peptides showed dose-dependent bactericidal activity against $P$. aeruginosa (Figure 3F). At $200 \mu \mathrm{g} /$ $\mathrm{ml}$, killing of $P$. aeruginosa strain 6206 by the 19-mer, 36-mer, and 10 -mer was $99.1 \%, 96.9 \%$, and $99.2 \%(P<0.0005)$.

In other experiments, mutations in $P$. aeruginosa LPS, a negatively charged cell wall component of Gram-negative bacteria, had only a minor impact on susceptibility of $P$. aeruginosa strain PAC1R (27) to the 19-mer KDAMP (Figure 3G).

Together these data suggest that KDAMP antimicrobial activity is retained under physiological conditions and requires a specific amino acid sequence(s) and a coil secondary structure but is independent of potential for transmembrane $\alpha$-helix formation, ability to form a hydrophobic face, and cationic charge.

KDAMP structure and bactericidal activity. Most known antimicrobial peptides require a specific secondary structure (e.g., $\alpha$-helix, $\beta$-sheet) for antimicrobial and other functions (28). However, we tested the hypothesis that this was not the case for these short K6A-derived fragments, given their predicted structural characteristics and their common anti-Pseudomonas activity, combined with a high glycine composition (35\% to $50 \%$ ) that would be expected to confer minimal conformational constraints. Circular dichroism (CD) spectroscopy was used to analyze the secondary structure of the 19-mer KDAMP, its scrambled control, and the 17-mer, 36-mer, and 10-mer derivatives. Peptides were analyzed after mixing with water or 2,2,2 trifluoroethanol (TFE), a helixpromoting solvent that mimics the hydrophobic microenvironment of cytoplasmic membranes. CD spectra showed that, in water or $50 \%$ TFE, each of the peptides displayed negative mean residue ellipticity values at the 200 -nm region, suggesting a random coil-like structure (Figure 4A), which was consistent with previous predictions (Table 2 ). When the TFE concentration was increased to $100 \%$, only the 36-mer adopted a helical confirmation; all others remained unstructured (Figure 4, A and B). Analysis of the spectra using the K2D2 program (29) confirmed that each of these bactericidal K6A-derived fragments (19-mer, 17-mer, and 10-mer) and the nonbactericidal scrambled 19-mer control exhibit a low to negligible helical content of regardless of environment hydrophobicity, suggesting that $\alpha$-helicity is not required for KDAMP bactericidal actions.

Since glycine residues were a common feature of naturally occurring KDAMPs (Table 2), and dominance of glycine has been identified in some nonmammalian antimicrobial peptides $(22,30)$, the contribution of 2 glycine residues to the bactericidal activity of synthetic KDAMPs was investigated. Two glycine residues (G-2 and G-8) of 10 -mer peptide (50\% glycine content) were substituted with alanine to interrupt consecutive glycine stretches. Thus, GGLSSVGGGS became GALSSVG $\underline{A} G S$, while maintaining similar amphipathicity and physiochemical properties. The site-directed mutant (G2A/G8A) showed reduced bactericidal activity against $P$. aeruginosa $(\sim 86 \%$ killing versus $>98 \%$ killing of control after 3 hours at $200 \mu \mathrm{g} / \mathrm{ml}, P<0.0001$ ) (Figure 4C), showing that these glycine residues contribute to activity.

KDAMP activity against other pathogens. The activity of synthetic KDAMPs was evaluated against other clinically important bacteria (Figure 4D). As expected, all K6A-derived peptides were active against $P$. aeruginosa. Antimicrobial activity was also observed toward other bacterial pathogens, but levels of activity varied between bacteria and peptides. The group A Streptococcus (Streptococcus pyogenes) was particularly susceptible. The 14-mer, the 19-mer, the two 18-mers (the 18-mer-N and the 18-mer-C, lacking the $\mathrm{N}$ - or C-terminal residue of the 19-mer, respectively), and the 36-mer were each highly effective against this clinically important pathogen (e.g., >99.9\% killing for the 14-mer, 18-mer-N, and 19 -mer, after 3 hours at $200 \mu \mathrm{g} / \mathrm{ml}, P<0.001)$. The 14 -mer $(>99.9 \%$ killing, $P<0.001)$ and the 18 -mer-N $(98.1 \%, P<0.0001)$ peptide also showed bactericidal activity against E. coli but less against Serratia marcescens (e.g., 14-mer, $32.4 \%$ killing, $P<0.001$ ). However, the 14-mer was highly effective in killing Staphylococcus aureus $(97.5 \%$, $P<0.0005)$ and Staphylococcus epidermidis (>99.7\%, $P<0.0001)$. These data show that KDAMP bactericidal activity extends beyond $P$. aeruginosa to other clinically important pathogens, suggesting that compositional flexibility may allow optimal activity against different pathogens. Indeed, it is possible that naturally occurring or synthetic KDAMPs may complement each other in situ to provide a broad-spectrum antimicrobial defense. 

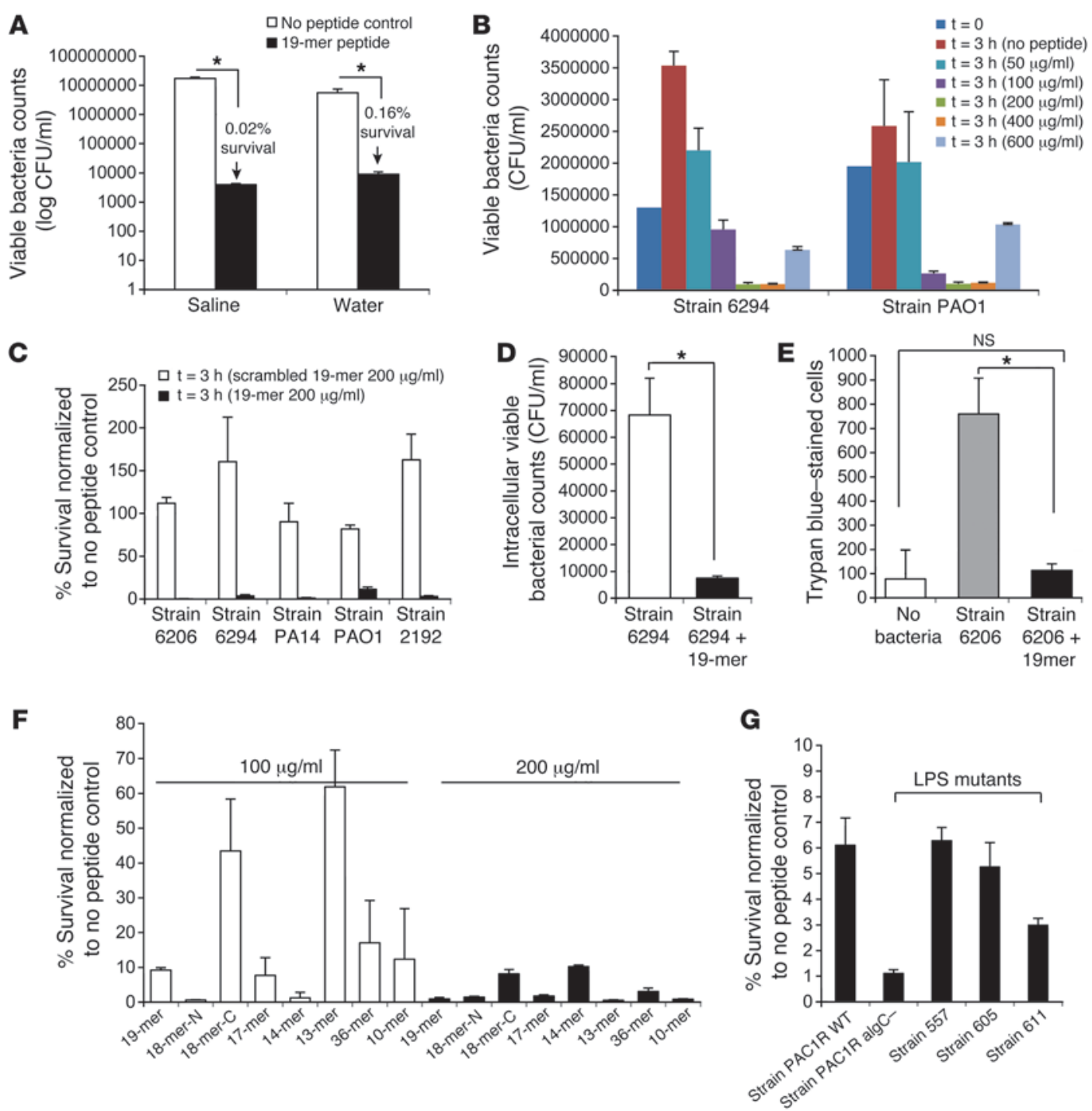

\section{Figure 3}

Synthetic analogs of K6A-derived peptides found in corneal epithelial cell lysates are bactericidal and cytoprotective against $P$. aeruginosa. (A) The 19-mer was tested against $P$. aeruginosa strain 6206 (clinical isolate) in physiological saline $(0.9 \% \mathrm{NaCl})$ or water and was found to be salt-tolerant ( ${ }^{\star} P<0.004$, versus no peptide control). (B) The 19-mer peptide showed dose-dependent bactericidal activity against resuspended lawn culture of $P$. aeruginosa invasive strains 6294 (clinical isolate) and PAO1 (laboratory strain), with optimal activity at $200 \mu \mathrm{g} / \mathrm{ml}$ under highsalt conditions. (C) At $200 \mu \mathrm{g} / \mathrm{ml}$, a scrambled control of the 19-mer peptide was inactive against $P$. aeruginosa. (D) Invasion of epithelial cells (strain 6294) ( ${ }^{\star} P=0.0008$, versus no peptide control) and (E) cytotoxicity toward epithelial cells (strain 6206) were prevented by the 19-mer K6A-derived peptide ( ${ }^{\star} P=0.0009$, versus no peptide control). (F) Synthetic variants of the 19-mer also showed dose-dependent bactericidal activity against $P$. aeruginosa strain 6206 (clinical isolate). Peptide as small as 10-amino acids retained bactericidal activity, despite a predicted loss of cationic charge (at pH 7.0), hydrophobic face, and ability to form a transmembrane helix (e.g., 13-mer, 10-mer). (G) Bactericidal activity of $19-\mathrm{mer}(200 \mu \mathrm{g} / \mathrm{ml})$ was only slightly affected by mutations in LPS for P. aeruginosa (strain PAC1R, serotype 03). PAC1RalgC- and PAC605 have incomplete LPS core oligosaccharide and are O antigen deficient (27), and PAC557 has a complete core but is $\mathrm{O}$ antigen deficient, while PAC611 has mutations only in the core (64).

KDAMP bactericidal activity involves bacterial cell wall/membrane disruption. To begin to understand how KDAMPs kill bacteria, $P$. aeruginosa were treated with a 19-mer peptide tagged with the fluorochrome TAMRA (5-(and-6)-carboxytetramethylrhodamine) (Invitrogen), and treated bacteria were stained with SYTOX Blue, a cell-impermeant dye. Fluorescence microscopy showed that untreated control bacteria and those treated with a scrambled 19-mer or TAMRA alone did not label with SYTOX, indicating that their cell walls/membranes remained intact, i.e., impermeable to the dye (Figure 5A). Those bacteria also remained motile (Supplemental Videos 1 and 2). In contrast, 19-mer-treated bacteria labeled with SYTOX (blue) and colabeled with TAMRA when the peptide was tagged (red) (Figure 5B) and were nonmotile (Supplemental Video 3). Bactericidal assays (viable counts) confirmed that TAMRA-tagged, or non-tagged, 19-mer-treated bacteria were dead, that killing activity of tagged-19-mer was similar to that of 

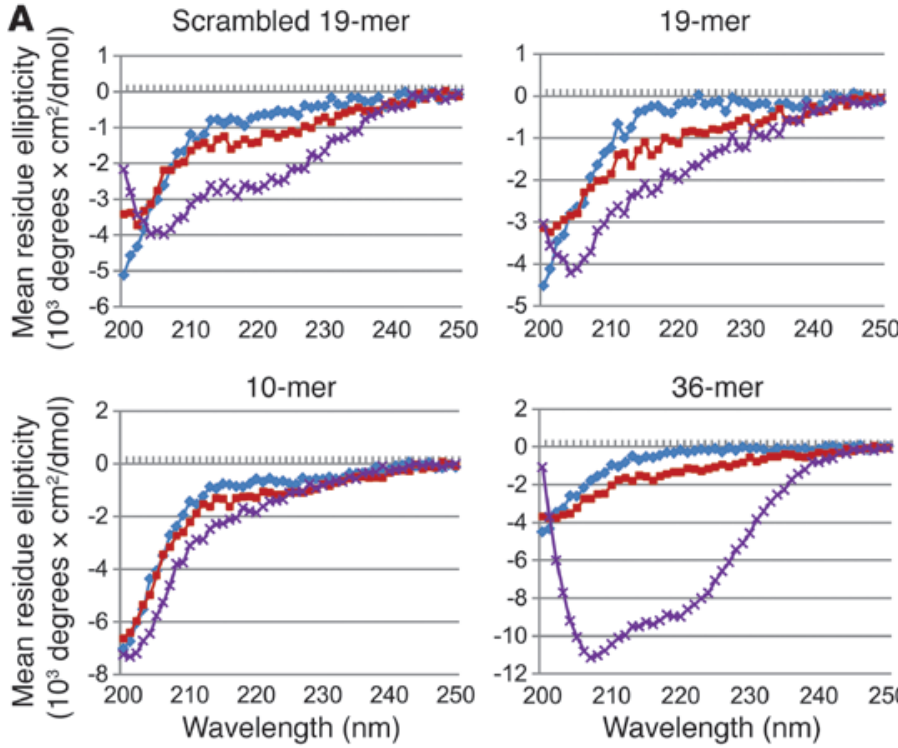

B

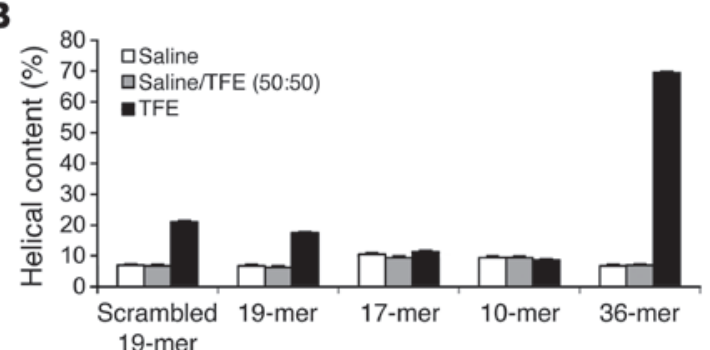
19-mer
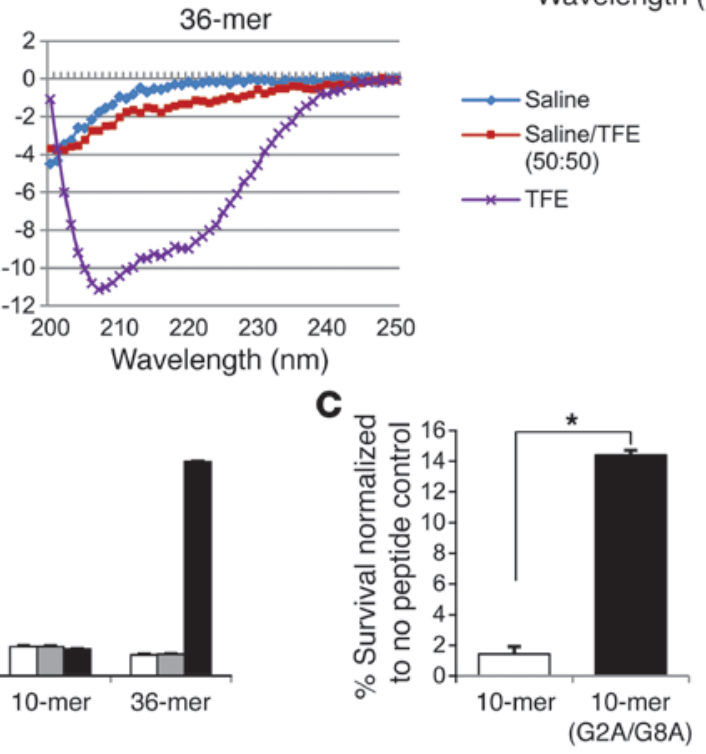

(G2A/G8A)
D
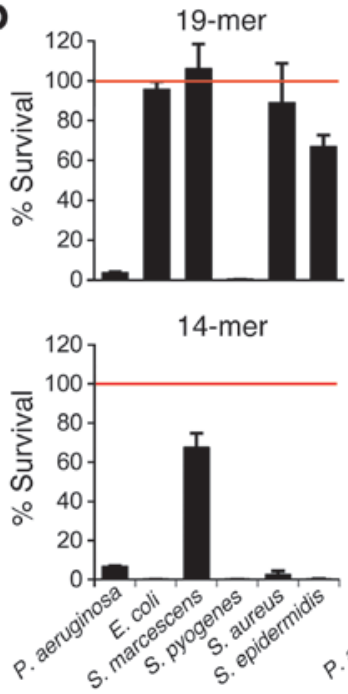

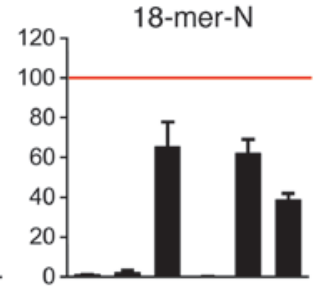

13-mer

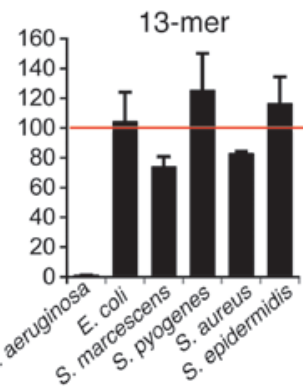

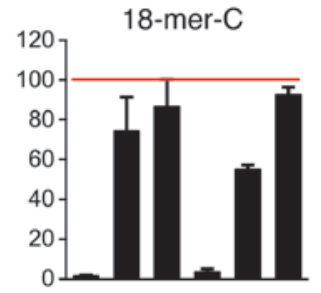

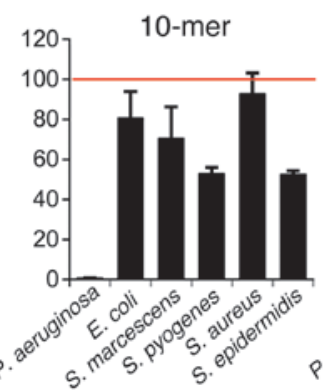

17-mer

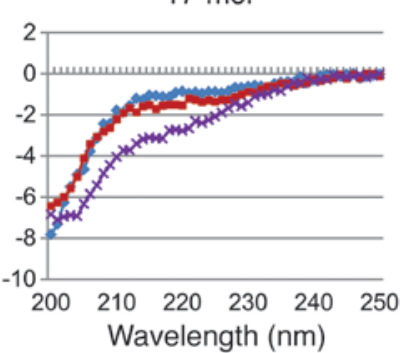

$\multimap$ Saline

—-Saline/TFE

(50:50)

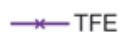

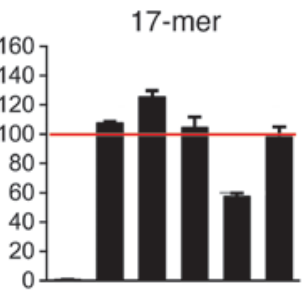

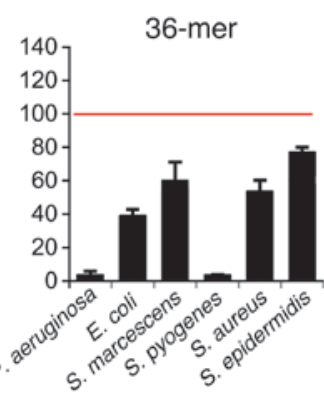

Figure 4

Synthetic analogs of K6A-derived peptides demonstrate conformational flexibility and target selectivity. (A) CD spectra of scrambled 19-mer (nonbactericidal control) as well as 19-mer, 17-mer, 10-mer, and 36-mer (bactericidal) in water, water/TFE (50:50), or TFE. Only 36-mer showed induced helical structure in TFE, others (with or without bactericidal activity) remained unstructured random coil-like peptides. (B) Analysis of the spectra using the K2D2 program (29) confirmed low to negligible helical content of scrambled 19-mer, active 19-mer, 17-mer, and 10-mer. (C) Glycine-to-alanine mutations (G2A and G8A) in the 10-amino acid peptide resulted in marked decrease of bactericidal activity against $P$. aeruginosa strain 6206 $\left({ }^{*} P<0.0001\right)$. (D) Activity spectra of the K6A-derived peptides against various Gram-positive and Gram-negative pathogenic or commensal bacteria. The 19-mer K6A-derived peptide showed even greater bactericidal activity against $S$. pyogenes than $P$. aeruginosa (200 $\mu \mathrm{g} / \mathrm{ml}, 3$ hours), but activity was lost with removal of $\mathrm{C}$ - and $\mathrm{N}$-terminal amino acids from 19-mer (17-mer peptide). E. coli was found to be susceptible to killing by the 14-mer and 18-mer-N, while S. marcescens was only minimally susceptible. $S$. aureus and S. epidermidis were both susceptible to killing by the 14-mer. the untagged peptide, and that TAMRA alone was inactive (Figure 5C). Interestingly, while TAMRA tagging did not affect activity of 19-mer against $P$. aeruginosa, it did impact 19-mer activity against other bacteria. For example, the TAMRA-tag enhanced 19-mer activity against $S$. marcescens and $E$. coli relative to unlabeled peptide $(P<0.005)$ but reduced activity against $S$. pyogenes $(P<0.005)$ (Supplemental Figure 1). Both of those results may reflect steric effects of the TAMRA-tag on the N-terminal residue, but further studies will be needed to understand their significance. At present, the data show that the K6A-derived 19-mer peptide binds bacterial cells and that it causes bacterial cell wall/membrane permeabilization, loss of swimming motility, and bacterial cell death.

KDAMP-induced bacterial cell permeabilization could directly cause cell death, as has been shown for cationic antimicrobial peptides (31). Alternatively, permeabilization may be secondary to peptide-induced cell death via another mechanism. Thus, the temporal profile of killing by the 19-mer peptide was examined. This was done using log-phase bacterial cultures and a concen- 


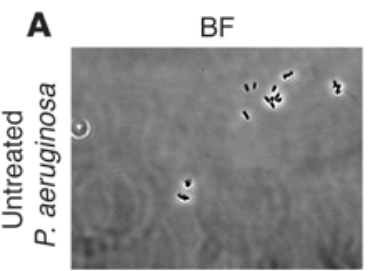

BF
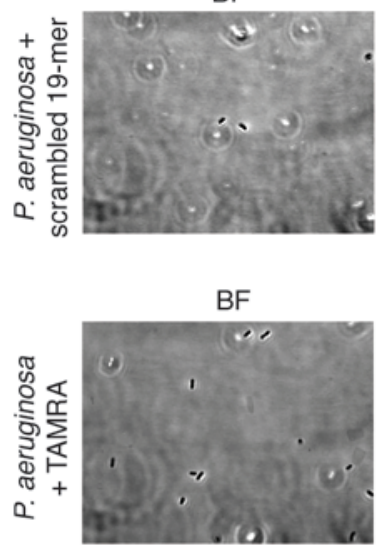

BF

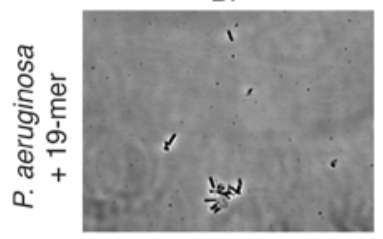

SYTOX Blue

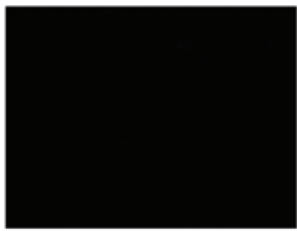

SYTOX Blue

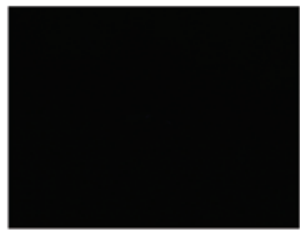

SYTOX Blue and TAMRA (merge)

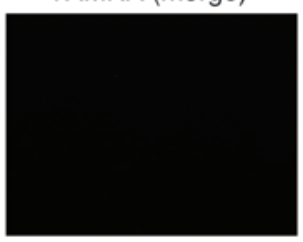

SYTOX Blue

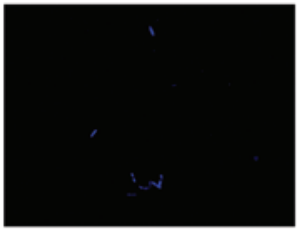

B

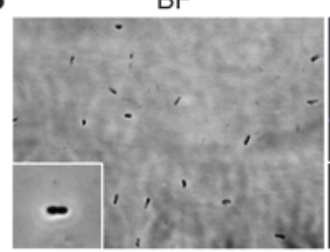

TAMRA-19-mer

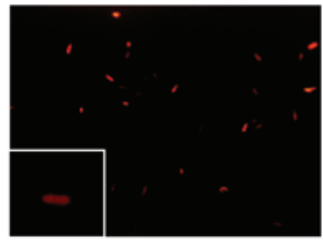

C

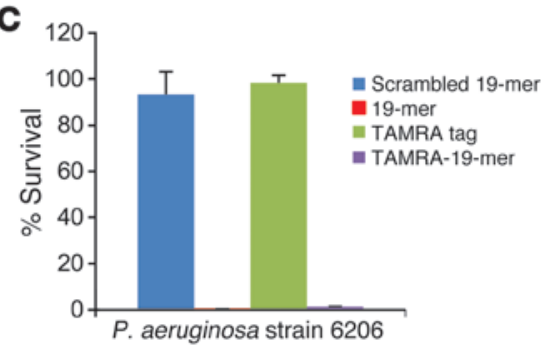

D

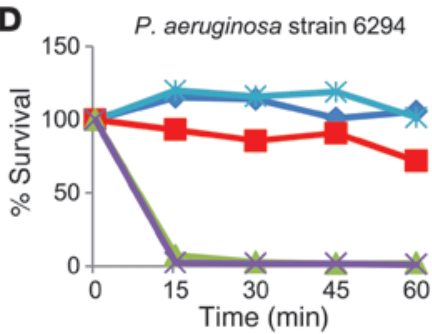

$\rightarrow$ No peptide $\longrightarrow 50 \mu \mathrm{g} / \mathrm{ml}$ $=10 \mu \mathrm{g} / \mathrm{ml} \longrightarrow 75 \mu \mathrm{g} / \mathrm{ml}$ $=-25 \mu \mathrm{g} / \mathrm{ml}$

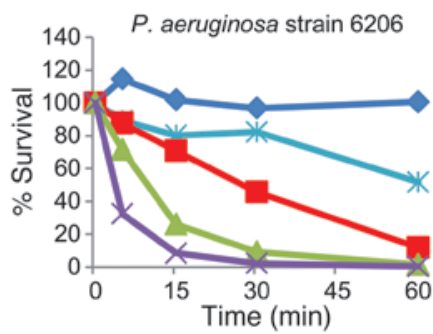

$\rightarrow$ No peptide $=40 \mu \mathrm{g} / \mathrm{ml}$ $-10 \mu \mathrm{g} / \mathrm{ml}=60 \mu \mathrm{g} / \mathrm{ml}$ $-20 \mu \mathrm{g} / \mathrm{ml}$

\section{E}

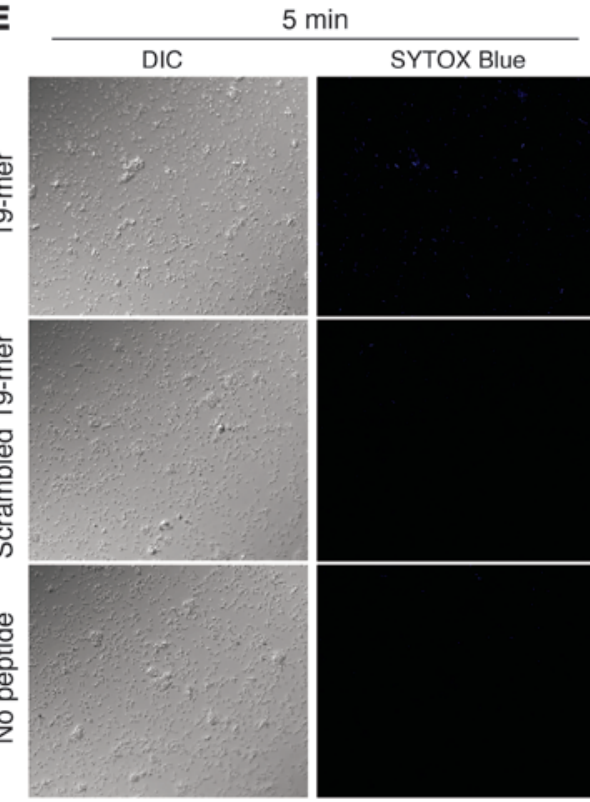

$15 \mathrm{~min}$

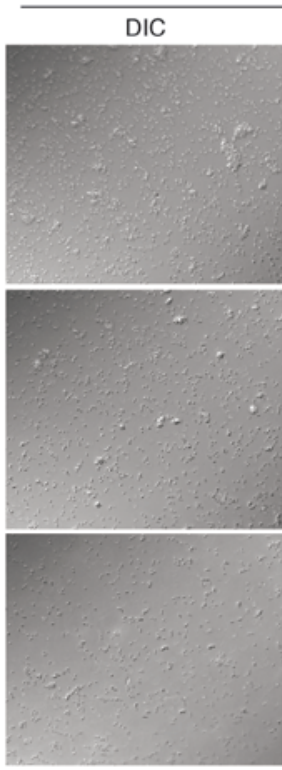

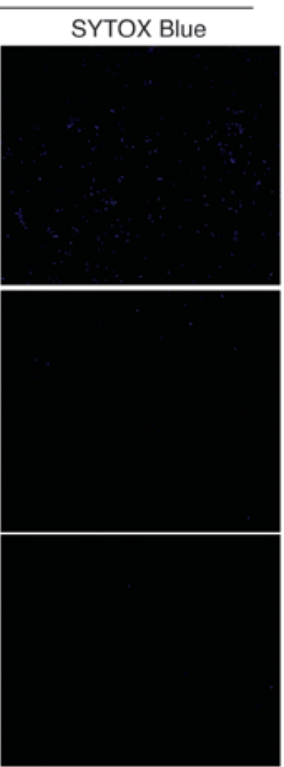




\section{Figure 5}

The K6A-derived 19-mer binds to bacterial cells and permeabilizes their cell membranes. (A) P. aeruginosa strain 6206 was either untreated (control) or treated with an equimolar concentration (110 $\mu \mathrm{M}$ each) of scrambled $19-\mathrm{mer}(200 \mu \mathrm{g} / \mathrm{ml})$, TAMRA $(50 \mu \mathrm{g} / \mathrm{ml})$, or $19-\mathrm{mer}(200 \mu \mathrm{g} / \mathrm{ml})$ for 3 hours and then stained with a cell-impermeant dye SYTOX Blue. Only the 19-mer-treated bacteria were stained with SYTOX Blue. TAMRA itself also did not bind to bacteria. Original magnification, $\times 1,000$. BF, bright field. (B) Strain 6206 was incubated with TAMRA-tagged (N-terminal) 19-mer $(110 \mu \mathrm{M}$, equivalent to $250 \mu \mathrm{g} / \mathrm{ml}$ ) for 3 hours then stained with SYTOX Blue. Fluorescence microscopy showed that the bacteria were labeled with the TAMRA-tagged 19-mer peptide (red) and SYTOX (blue) and that these labels colocalized. Original magnification, $\times 1,000$. Highermagnification images are shown in inset panels (original magnification, $x \sim 2,000)$. (C) TAMRA-tagged 19-mer had similar bactericidal activity to that of unlabeled peptide (93.2\% and $98.4 \%$, respectively, $P<0.05$ ) after 3 hours at $110 \mu \mathrm{M}$ against $P$. aeruginosa (strain 6206). TAMRA alone was inactive. (D) Rapid and extensive killing action of the 19-mer against $P$. aeruginosa strain 6294 and strain 6206. (E) SYTOX staining of $P$. aeruginosa 6206 at 5 and 15 minutes after treatment with the 19-mer KDAMP at $75 \mu \mathrm{g} / \mathrm{ml}$. Bacteria incubated with the scrambled 19-mer or untreated served as controls. DIC, differential interference contrast. Original magnification, $\times 400$.

tration of $10^{8} \mathrm{CFU} / \mathrm{ml}$ of $P$. aeruginosa suspended in saline. The 19 -mer peptide killed $71.7 \%$ and $91.7 \%$ of strain 6206 after 5 and 15 minutes, respectively, and $98 \%$ of strain 6294 after 15 minutes (Figure 5D). Antimicrobial proteins or peptides that exert killing effects via inhibition of macromolecular synthesis, i.e., DNA, RNA, and/or protein, generally require at least 30 minutes of exposure for maximal impact on bacterial viability (>90\% killing) $(32,33)$. The rapid action of the 19-mer suggested that direct membrane disruption was involved in the mechanism by which it killed $P$. aeruginosa. That hypothesis was supported by the observation of SYTOX-labeled $P$. aeruginosa at 5 and 15 minutes after treatment with the 19-mer KDAMP (Figure 5E).

\section{Discussion}

Keratins have long been recognized as indispensable structural materials that maintain cell integrity and resilience. Here we show a role for human keratins in epithelial innate immunity as a source of endogenous antimicrobial peptides. Specifically, the data show that short peptide fragments derived from the $\mathrm{C}$ terminus of hK6A are found within differentiated human corneal epithelial cells, that these peptides exert antimicrobial activity against multiple bacterial pathogens in vitro, and that depletion of $\mathrm{K} 6 \mathrm{~A}$ in vivo reduces corneal defense against bacterial attachment. Antimicrobial activity of these coiled, glycine-rich peptides (termed KDAMPs) is not constrained by stringent secondary structure or net charge requirements. Direct visualization showed that KDAMPs bind to $P$. aeruginosa, that they induce cell wall/membrane permeabilization, and that they inhibit bacterial motility. Together, we believe these data establish a new role for cytokeratin 6 in protecting mammalian epithelia from bacterial infection.

Structure-activity and imaging studies with K6A-derived peptide fragments and $P$. aeruginosa provided initial insights into KDAMP mechanism(s) of action. Firstly, antimicrobial activity of K6A-derived peptides was unaffected by changes in charge or predicted hydrophobic moment, and all but one (36-mer) lacked an $\alpha$-helical secondary structure in conditions mimicking the environment of bacterial cell membranes. This contrasts with many other previously identified types of antimicrobial peptide for which cationic charge, hydrophobicity, and $\alpha$-helix formation are important criteria in their antimicrobial function $(25,34)$. Proposed mechanisms for these requirements include binding to anionic bacterial cell membranes with disruption involving pore formation. However, amphipathicity of antimicrobial peptides can have a more significant role in determining bactericidal activity than hydrophobicity or $\alpha$-helical content, as shown against E. coli (35). Moreover, rapid action of some antimicrobial peptides involves membrane disintegration via the "carpet" mechanism, in which peptides accumulate to critical thresholds on bacterial membrane surfaces (36). Selectivity between host and microbial cells can also be based on electrochemical potential across the bacterial cytoplasmic membrane due to the proton flux (transmembrane potential) (37). Studies have also suggested that more specific interactions within bacterial cell walls or membranes help to define antimicrobial peptide activity (38). For example, binding of the antimicrobial peptide nisin can be mediated by peptidoglycan-associated lipid II (39), and salivary histatins bind a $67-\mathrm{kDa}$ surface protein of Candida albicans (40). Specific cell wall/membrane targeting may explain some of the differences in the spectrum of K6A-derived peptide activity, e.g., the 19-mer is effective against S. pyogenes but not S. aureus or E. coli, both of which are highly susceptible to the 14-mer. Scrambling the sequence of the 19-mer all but eliminated activity against $P$. aeruginosa, even though predicted charge and coil structure were similar to those of the active peptide. Although the scrambled 19-mer lost ability to form a transmembrane helix, that predicted property was not evident for other smaller KDAMPs (e.g., 13-mer, 10-mer) that showed similar activity against $P$. aeruginosa as the 19-mer. The scrambled 19-mer did show a reduced hydrophobic moment $(\mu \mathrm{H})$ of $0.138 \mu \mathrm{H}$ compared with that of the active 19-mer $(0.279 \mu \mathrm{H})$ and other active KDAMPs $(0.219 \mu \mathrm{H}$ or greater). Studies with fallaxin-based antimicrobial peptides have shown that active and inactive peptides could be grouped according to hydrophobic moment data, although these data alone were not helpful in predicting activity (41). However, for citropin-based antimicrobial peptides, increased antimicrobial activity and improved bacterial membrane binding (using lipid extracts) were associated with increased hydrophobic moment (42). Thus, differences in the hydrophobic moment of KDAMPs may be helpful in further analysis of their structure-activity relationships.

Use of TAMRA-labeled K6A-derived peptides and SYTOX showed these that peptides bind $P$. aeruginosa and that they cause cell wall/membrane permeabilization. The specific mechanism for cell wall/membrane disruption by K6A-derived peptides is not yet known. Differences between predicted KDAMP structural features (e.g., charge, hydrophobicity, secondary structure, etc.), compared with those of other known antimicrobial peptides, suggest the possibility that the mechanism is novel.

Glycine predominates the amino acid composition of the K6A-derived peptides (up to $50 \%$ of the 10 -mer), and substitutions of glycine residues with alanine at positions 2 and 8 reduced bactericidal activity of keratin-derived (K6A-derived) fragments. This contrasts with early magainin antimicrobial peptides, for which glycine-alanine substitution promotes antimicrobial activity by increasing $\alpha$-helix formation (43). However, it is consistent with the results of structure-activity experiments that revealed that $\alpha$-helical structure was not critical for KDAMP activity. A potential role of glycine repeats in KDAMP structure would be that they 
confer high structural flexibility (degrees of freedom) to these molecules to enable their antimicrobial action. Further studies will be needed to elucidate the role of glycine in the antimicrobial activity of K6A-derived peptides and whether peptides derived from keratins $\mathrm{K} 5$, K15, and K19, which were also detected in bactericidal cell lysate fractions and which also show glycine-rich tandem repeats in $\mathrm{N}$ - or C-terminal regions (acidic or basic keratins, respectively) (Supplemental Figures 2 and 3), are also antimicrobial.

Keratins are an ancient and extremely diverse set of proteins (44). In humans, keratins comprise a large family (54 functional genes) distributed intracellularly and extracellularly among multiple tissues, including skin, teeth, hair, nails, and mucosal surfaces (45, 46). Within epithelial cells, basic (type II) and acidic (type I) cytokeratins work as complementary pairs to form heteropolymeric intermediate filaments of the cytoskeleton and are key structural components of human cells and tissues. Cytokeratins also play roles in wound healing and tissue regeneration (47) in intracellular signaling and apoptosis (46). Discovery of antimicrobial and cytoprotective properties for K6A-derived peptides could advance our understanding of the functional significance of cytokeratin 6, and other keratins, in general. For example, it might explain the universal presence of keratins in cells and tissues of virtually all species and their diversity within species. Interestingly, a previous study reported that TR65, an antibacterial, pore-forming glycoprotein found in the skin mucous of the rainbow trout, shows strong homology to the trout type II epidermal cytokeratin E1 and is rich in glycine and serine residues (48). Moreover, the authors of that paper suggested that there may be a role for human cytokeratins in innate immunity, given the previously reported increased expression of several cytokeratins in respiratory epithelial cells in response to $P$. aeruginosa strain PAO1 (49). Another study showed that PiBP-5, a 5.7-kDa glycine-, serine-, and threonine-rich antibacterial peptide derived from porcine bladder mucosa, has strong homology to human cytokeratin 7 (50). The abundance of cytokeratin cytoskeletal proteins, and the constant and rapid manner in which full-length cytokeratin monomers are released from their filamentous assembly (51), could support a cellular demand for antimicrobial peptides to help defend human mucosal epithelia against microbial pathogens. It is possible that antimicrobial activity contributes to the demonstrated role of cytokeratin 6 in wound healing and tissue repair $(52,53)$. It is also of interest that dysfunctional intermediate filament turnover has been implicated in the pathogenesis of various internal conditions, including infectious hepatitis, pancreatitis, and inflammatory bowel disease (54).

Turnover of intermediate filaments, and soluble keratin proteins, in epithelial cells is a highly regulated and complex process that is known to involve the ubiquitin-proteasome pathway (UPP) $(55,56)$. It is not yet known whether the UPP contributes to the generation or degradation of KDAMPs. Our results (Figure $2 \mathrm{~A}$ ) showed a calcium-dependent effect on the generation of fragments from full-length K6A in human corneal epithelial cells, and UPP degradation of host proteins can be increased by elevated intracellular calcium (57). However, generation and degradation of KDAMPs could also reflect the activities of calcium-dependent proteases, e.g., calpains, which are known to target keratins (58, $59)$ and are present in corneal epithelial cells and other ocular tissues (60). Further studies are underway to investigate the mechanisms of KDAMP generation and regulation in epithelial cells.

In conclusion, this study reveals what we believe to be a novel function for human keratins as a source of endogenous antimicro- bial peptides contributing to antimicrobial activity of cell lysates and defense against bacterial adherence in vivo. Small synthetic analogs of these peptides exert broad-spectrum antimicrobial activity against diverse human pathogens, including $P$. aeruginosa, E. coli, S. pyogenes, and $S$. aureus. These peptides are active under physiological conditions and induce bacterial cell wall/membrane permeabilization after binding, which does not require cationic charge or $\alpha$-helix formation but does require glycine residues. Further studies will be required to determine the mechanistic details of their bactericidal activity, whether other forms of keratin also give rise to KDAMPs, the mechanism(s) by which they are generated in vivo, and their functional significance in the innate defense of mucosal epithelia and epithelial homeostasis. KDAMPs may also be of value as robust, biocompatible, and efficacious therapeutic agents for combating infection.

\section{Methods}

Bacterial strains. P. aeruginosa corneal clinical isolates 6294 (invasive) and 6206 (cytotoxic), cystic fibrosis clinical isolate 2192, and laboratory strains PAO1 (invasive) and PA14 (cytotoxic) were used in this study. PAC1R and its series of isogenic LPS mutants (PAC1RalgC:tet, 557, 605, 611) were provided by Gerald B. Pier (Harvard Medical School, Boston, Massachusetts, USA). For antimicrobial spectrum analysis, E. coli (ATCC 25922), S. marcescens (ATCC 43862), S. epidermidis (ATCC 12228), S. aureus (ATCC 29213), and S. pyogenes (ATCC 19615) were used. For antimicrobial activity assays, lawn culture of $P$. aeruginosa was grown on tryptic soy agar plates at $37^{\circ} \mathrm{C}$ for 16 hours, while other bacteria were grown on nutrient agar plates for 16 hours at media and conditions specified by ATCC. Starting inocu$\mathrm{lum}$, at a concentration of approximately $10^{8} \mathrm{CFU} / \mathrm{ml}$, was prepared fresh by suspending bacteria in serum-free Keratinocyte Basal Medium (KBM) (Lonza Inc.) until $\mathrm{OD}_{650}$ reading was approximately 0.1 . Specific bacterial concentration used in antimicrobial and cytoprotective assays was prepared by 100 -fold dilution of this starting inoculum in the indicated test media $\left(\sim 10^{6} \mathrm{CFU} / \mathrm{ml}\right)$. For experiments involving peptide effects on bacterial swimming motility or the time course of bacterial killing, broth cultures of $P$. aeruginosa were prepared by subculturing overnight culture in tryptic soy broth at $37^{\circ} \mathrm{C}$ until $\mathrm{OD}_{600}$ reading was approximately 0.3 (log phase). Bacteria were washed and resuspended in saline to an $\mathrm{OD}_{650}$ reading of approximately $0.1\left(\sim 10^{8} \mathrm{CFU} / \mathrm{ml}\right)$.

Cell culture and lysate fractionation. hTCEpi cells (15) were maintained at $37^{\circ} \mathrm{C} / 5 \% \mathrm{CO}_{2}$ in regular keratinocyte growth medium (KGM-2) containing $0.15 \mathrm{mM} \mathrm{CaCl}_{2}$ (Lonza). hTCEpi cells in antibiotic-free KGM-2 media were grown to $90 \%$ confluence in 96 -well tissue culture-treated plates and then switched high-calcium antibiotic-free KGM-2 media (containing $1.15 \mathrm{mM} \mathrm{CaCl}_{2}$ for 32 hours. Cells were then lysed in $25 \mu \mathrm{KBM}$ (Lonza) per well (for antimicrobial and cytoprotective activity assays) or $100 \mathrm{mM}$ Tris-HCl ( $\mathrm{pH}$ 8.5) (for mass spectrometry) by 3 cycles of freeze and thaw. Crude lysate was pooled and confirmed to have equal total protein concentration using a Bicinchoninic Acid Assay Kit (Pierce Biotechnology Inc., Thermo Scientific). Serial fractionation of crude lysate was performed at $4^{\circ} \mathrm{C}$ using sterile water-prerinsed Microcon centrifugal filter devices, with membrane cutoffs at 100, 10, and $3 \mathrm{kDa}$ (Millipore). Fresh vehicle was added back to all lysate fractions to maintain equal volume to that of their original crude lysates.

Mass spectrometry. Mass spectrometry was performed at the Proteomics/ Mass Spectrometry Laboratory at University of California, Berkeley. A nano LC column was packed in a 100- $\mu \mathrm{m}$ inner diameter glass capillary with an emitter tip. The column consisted of $10 \mathrm{~cm}$ of Polaris $\mathrm{c} 185$ - $\mu \mathrm{m}$ packing material (Varian). The column was loaded by use of a pressure bomb and washed extensively with buffer A (see below). The column was then directly 
coupled to an electrospray ionization source mounted on a Thermo-Fisher LTQ XL linear ion trap mass spectrometer. An Agilent 1200 HPLC equipped with a split line so as to deliver a flow rate of $30 \mathrm{nl} / \mathrm{min}$ was used for chromatography. Peptides were eluted with a 90 -minute gradient from $100 \%$ buffer A to $60 \%$ buffer B. Buffer A was 5\% acetonitrile $/ 0.02 \%$ heptafluorobutyric acid (HBFA); buffer B was $80 \%$ acetonitrile $/ 0.02 \%$ HBFA. Collision-induced dissociation and electron transfer dissociation spectra were collected for each $m / z$. The SEQUEST and DTASELECT programs were used to identify peptides and proteins from the human database $(61,62)$.

Bioinformatics. Peptide sequences were analyzed using web-based tools hosted on the Expert Protein Analysis System (ExPASy) proteomics server of the Swiss Institute of Bioinformatics (http://ca.expasy.org/tools/ \#proteome). Specifically, ProtParam was used to compute theoretical pI, NetSurfP was used for secondary structure prediction, TMpred was used for transmembrane helices prediction, HeliQuest was used for amphipathicity and net charge computation as well as helical wheel presentations. Clustal Omega was used to align protein sequences.

Western blotting. hTCEpi cells were lysed on plates directly by tricine gel loading buffer containing SDS and $\beta$-mercaptoethanol (Bio-Rad). Detection of full-length and fragmented hK6A and GADPH proteins in the crude lysate (containing $10 \mu \mathrm{g}$ of total protein) were performed by standard Western blotting using rabbit anti-19-mer antiserum (prepared by New England Peptide) and rabbit polyclonal anti-GAPDH antibody (sc25778; Santa Cruz Biotechnology Inc.), respectively, followed by goat anti-rabbit IgG-HRP secondary antibody (Bio-Rad). The rabbit anti19-mer antiserum also recognized murine cytokeratin 6 (data not shown). siRNA knockdown and real-time PCR. For in vitro knockdown, transfection (6 hours) in 96-well plate format was performed when hTCEpi cells were $80 \%$ confluent using Lipofectamine RNAi Max (Invitrogen) and siRNAs (10 pmol in $100 \mu \mathrm{l})$ against hK6A (5'-CGAAGGCGUUGGACAAGUC-3', 5'-GAACAAGGUUGAACUGCAA-3', 5'-GCAGUUCCACCAUCAAGUA-3', and 5'-GAGAUCAACUUCCUGAGAG-3'; ON-TARGETplus SMARTpool L-012116-00-0005; Dharmacon) or scrambled control (ON-TARGETplus Non-targeting Pool D-001810-10-05; Dharmacon), followed by 16 hours of recovery in antibiotic-free KGM-2, and then 16 hours of differentiation in high-calcium antibiotic-free KGM-2 (containing $1.15 \mathrm{mM} \mathrm{CaCl}_{2}$ ). To collect lysate for antimicrobial assays, cells were lysed in $25 \mu \mathrm{l}$ saline per well $(0.9 \% \mathrm{NaCl})$ by 3 cycles of freeze and thaw, and crude lysate was pooled and confirmed to have equal total protein concentration prior to use. For in vivo knockdown, C57BL/ 6 wild-type mice (Charles River) were subconjunctivally injected with siRNAs in PBS $(5 \mu \mathrm{l}$ of $8 \mu \mathrm{M}$ per eye) against mouse K6A (5'-GCUCUUGGCUUCCUCGUAA-3', 5'-GCUCAGAGAAGUCGGGCUG-3', 5'-GGUUGAAUGGUGAAGGUGU-3', 5'-GAUGUAAGUUUCUGCUCAU-3'; ON-TARGETplus SMARTpool L-061465-01-0005; Dharmacon) or scrambled control (ON-TARGETplus Non-targeting Pool D-001810-10-05; Dharmacon). Injections were performed once a day for 2 days before mice were sacrificed by lethal injection of anesthetic cocktail (21 mg/ml ketamine, $2.4 \mathrm{mg} / \mathrm{ml}$ xylazine, and $0.3 \mathrm{mg} / \mathrm{ml}$ acepromazine). Whole eyes were enucleated and PBS-rinsed to exclude tear fluid, followed by incubation with $200 \mu \mathrm{l} \mathrm{GFP-expressing} P$. aeruginosa strain PAO1 (i.e., $10^{11} \mathrm{CFU} / \mathrm{ml}$ of PAO1-GFP) for 3 hours at $35^{\circ} \mathrm{C}$, and then imaged using combined 2-photon confocal microscopy as previously described (63). To confirm successful knockdown, total RNA was isolated using the RNeasy Mini Kit (Qiagen), and $1 \mu \mathrm{g}$ was used for cDNA synthesis using the Verso cDNA Synthesis Kit (Dharmacon). K6A and GAPDH (internal control) were amplified from cDNA $(0.5 \mu \mathrm{l}$ of each cDNA sample per $10 \mu \mathrm{l}$ of PCR reaction) using QuantiTect SYBR Green PCR Master Mix and Primer Assays (Qiagen). Samples were analyzed in triplicates in 3 independent runs using a real-time detection system (Bio-Rad). Transcript levels of K6A were normalized to those of GAPDH (human) or Rn18s (mouse).
Peptide synthesis. All peptides (with or without N-terminal TAMRA-tag) were synthesized by Biomatik to $>95 \%$ purity and verified by HPLC and MS. Stock solutions were prepared in sterile water or DMSO, and aliquots were kept at $-20^{\circ} \mathrm{C}$ and limited to 1 thaw prior to use.

Antimicrobial activity assay. Bacteria $\left(60 \mu \mathrm{l} ; 10^{6} \mathrm{CFU} / \mathrm{ml}\right.$ of suspended lawn culture) in whole lysate, lysate fractions, and saline, with indicated peptides (as specified in figure legends) as well as the corresponding vehicle controls, were incubated in triplicates at $37^{\circ} \mathrm{C}$ for 3 hours. Serial dilutions of the samples at time 0 and 3 hours were plated on nutrient agar plates and incubated at $37^{\circ} \mathrm{C}$ overnight for viable bacterial counts (CFU/ml). The percentage of bacterial killing at 3 hours was determined as follows: (bacterial counts without peptide - bacterial counts with peptide)/bacterial counts without peptide $\times 100 \%$. Shorter incubation times (from 5 to 60 minutes) were used in some experiments (see Figure 5).

Invasion and cytotoxicity assay. To assess protective activity against bacterial invasion, high-calcium-treated hTCEpi cells were incubated with $P$. aeruginosa clinical isolate $6294\left(40 \mu \mathrm{l} /\right.$ well; $10^{6} \mathrm{CFU} / \mathrm{ml}$ in crude lysates/lysate fractions versus KBM control for 3 hours or $10^{8} \mathrm{CFU} / \mathrm{ml}$ in peptide-containing saline versus no-peptide saline control for 2 hours), followed by gentamicin treatment $(200 \mu \mathrm{g} / \mathrm{ml}$ for 1 hour). Viable intracellular bacteria was collected with $0.25 \%$ Triton-X in PBS $(100 \mu \mathrm{l} /$ well $)$ and quantified by plating on tryptic soy agar. To assay protection against bacterial cytotoxicity, P. aeruginosa clinical isolate 6206 was used instead $\left(40 \mu \mathrm{l} /\right.$ well; $10^{6} \mathrm{CFU} / \mathrm{ml}$ for 3 hours). Dead cells were quantified by trypan blue (0.04\%) staining.

$\mathrm{CD}$ spectroscopy and analysis. CD spectra were recorded at $25^{\circ} \mathrm{C}$ with a spectropolarimeter (model 410, Biomedical Inc.) from 190 to $300 \mathrm{~nm}$ using a $0.1-\mathrm{cm}$ path-length quartz cuvette. Peptides were dissolved in pure water or $50 \%$ water $/ 50 \%$ TFE mixture or pure TFE to a final concentration of $0.1 \mathrm{mg} / \mathrm{ml}$. Three scans were conducted at $1-\mathrm{nm}$ intervals and 1 -s intervals. Spectra were averaged and subtracted for blank control, and mean residue ellipticity values were presented. $\mathrm{CD}$ data were further analyzed using the web-based K2D2 program.

Phase-contrast and fluorescence microscopy. To assess bacterial motility, P. aeruginosa clinical isolate $6206\left(700 \mu \mathrm{l} ; 10^{8} \mathrm{CFU} / \mathrm{ml}\right.$ of log-phase culture in saline) was incubated with or without peptide $(100 \mu \mathrm{g} / \mathrm{ml}$ synthetic 19 -mer peptide or its scrambled control peptide) at $37^{\circ} \mathrm{C}$ for 15 minutes in the presence of hTCEpi cells in 12-well tissue culture plates. Real-time bacterial motility was visualized with an Olympus IX70 epifluorescent microscope using a $\times 40$ objective and phase contrast (total magnification, $\times 400$ ). To assess peptide binding and membrane permeabilization, bacteria $\left(200 \mu \mathrm{l} ; 10^{6} \mathrm{CFU} / \mathrm{ml}\right.$ of suspended lawn culture) were incubated at $37^{\circ} \mathrm{C}$ for 2.5 hours with or without indicated peptides, including TAMRA-tag peptides and TAMRA tag control (Invitrogen) at the equimolar concentration of $110 \mu \mathrm{M}$, followed by 30 minutes of incubation with the impermeant SYTOX blue nucleic acid stain ( $5 \mu \mathrm{M}$; Invitrogen). Bacteria were pelleted by centrifugation, and supernatant was removed before resuspension in $10 \mu \mathrm{l}$ saline. Bacteria were visualized by phase-contrast microscopy, SYTOX blue stain, and TAMRA fluorescence under a $\times 100$ objective (total magnification, $\times 1,000$ ).

Statistics. Data are expressed as mean \pm SD, calculated from triplicate samples per group in each experiment. Statistical significance of differences between 2 groups was determined by the Student's $t$ test ( 2 tailed). $P<0.05$ was considered significant. All experiments were repeated at least 3 times, and representative experiments are shown in each figure.

Study approval. All animal procedures were performed in strict accordance with protocols approved by the Animal Care and Use Committee, University of California, Berkeley, which is an AAALAC-accredited institution.

\section{Acknowledgments}

This work was supported by a Grand Challenges Exploration Grant from the Bill and Melinda Gates Foundation and by NIH grant 
RO1-EY011221. We wish to thank Gerald B. Pier (Harvard Medical School) for providing P. aeruginosa strain PAC1R and its LPS-defective mutants; Lori Kohlstaedt (Proteomics/Mass Spectrometry Laboratory, University of California, Berkeley) and Susan Marqusee (QB3 Institute, University of California, Berkeley) for instrumentation and helpful advice; and Arjay Clemente, Jong Hun Kim, Gary Chan, Angela Wong, and Robin So for technical assistance.
Received for publication April 20, 2012, and accepted in revised form July 26, 2012.

Address correspondence to: Suzanne M.J. Fleiszig, University of California, Berkeley, 688 Minor Hall, Berkeley, California 947202020, USA. Phone: 510.643.0990; Fax: 510.643.5109; E-mail: fleiszig@berkeley.edu.
1. Tlaskalova-Hogenova $\mathrm{H}$, et al. Commensal bacteria (normal microflora), mucosal immunity and chronic inflammatory and autoimmune diseases. Immunol Lett. 2004;93(2-3):97-108.

2. Tam A, Wadsworth S, Dorscheid D, Man SF, Sin DD. The airway epithelium: more than just a structural barrier. Ther Adv Respir Dis. 2011;(4):255-273.

3. Kufer TA, Sansonetti PJ. Sensing of bacteria: NOD a lonely job. Curr Opin Microbiol. 2007;10(1):62-69.

4. Coll RC, O'Neill LA. New insights into the regulation of signalling by toll-like receptors and nod-like receptors. J Innate Immun. 2010;2(5):406-421.

5. Uematsu S, Fujimoto K. The innate immune system in the intestine. Microbiol Immunol. 2010; 54(11):645-657.

6 . Beutler B. Inferences, questions and possibilities in Toll-like receptor signalling. Nature. 2004; 430(6996):257-263.

7. Beutler B. Microbe sensing, positive feedback loops, and the pathogenesis of inflammatory diseases. Immunol Rev. 2009;227(1):248-263.

8. Stapleton F, et al. The incidence of contact lens-related microbial keratitis in Australia. Ophthalmol ogy. 2008;115(10):1655-1662.

9. Keay L, et al. Microbial keratitis predisposing factors and morbidity. Ophthalmology. 2006;113(1):109-116.

10. Mun JJ, et al. Clearance of Pseudomonas aeruginosa from a healthy ocular surface involves surfactant protein $\mathrm{D}$ and is compromised by bacterial elastase in a murine null-infection model. Infect Immun. 2009;77(6):2392-2398.

11. Ramphal R, McNiece MT, Polack FM. Adherence of Psendomonas aeruginosa to the injured cornea: a step in the pathogenesis of corneal infections. Ann Ophthalmol. 1981;13(4):421-425.

12. Augustin DK, et al. Role of defensins in corneal epithelial barrier function against Pseudomonas aeruginosa traversal. Infect Immun. 2011;79(2):595-605.

13. McDermott AM. The role of antimicrobial peptides at the ocular surface. Ophthalmic Res. 2009;41(2):60-75.

14. Jager S, Stange EF, Wehkamp J. Antimicrobial peptides in gastrointestinal inflammation. Int Inflam. 2010;2010:910283.

15. Robertson DM, et al. Characterization of growth and differentiation in a telomerase-immortalized human corneal epithelial cell line. Invest Ophthalmol Vis Sci. 2005;46(2):470-478.

16. Zasloff M. Antimicrobial peptides of multicellular organisms. Nature. 2002;415(6870):389-395.

17. Karring H, Thogersen IB, Klintworth GK, MollerPedersen T, Enghild JJ. A dataset of human cornea proteins identified by Peptide mass fingerprinting and tandem mass spectrometry. Mol Cell Proteomics. 2005;4(9):1406-1408.

18. Leptihn S, Har JY, Wohland T, Ding JL. Correlation of charge, hydrophobicity, and structure with antimicrobial activity of S1 and MIRIAM peptides. Biochemistry. 2010;49(43):9161-9170.

19. Gautier R, Douguet D, Antonny B, Drin G. HELIQUEST: a web server to screen sequences with specific alpha-helical properties. Bioinformatics. 2008;24(18):2101-2102.

20. Petersen B, Petersen TN, Andersen P, Nielsen M, Lundegaard C. A generic method for assignment of reliability scores applied to solvent accessibility predictions. BMC Struct Biol. 2009;9:51.

21. Hofmann K, Stoffel W. TMBASE - A database of membrane spanning protein segments. Biol Chem
Hoppe-Seyler. 1993;374:166.

22. Thomas S, Karnik S, Barai RS, Jayaraman VK, Idicula-Thomas S. CAMP: a useful resource for research on antimicrobial peptides. Nucleic Acids Res. 2010;38(Database issue):D774-D780.

23. Scudiero O, et al. Novel synthetic, salt-resistant analogs of human beta-defensins 1 and 3 endowed with enhanced antimicrobial activity. Antimicrob Agents Chemother. 2010;54(6):2312-2322.

24. Turner J, Cho Y, Dinh NN, Waring AJ, Lehrer RI. Activities of LL-37, a cathelin-associated antimicrobial peptide of human neutrophils. Antimicrob Agents Chemother. 1998;42(9):2206-2214.

25. Reynolds NL, et al. Peptide fragments of a betadefensin derivative with potent bactericidal activity. Antimicrob Agents Chemother. 2010;54(5):1922-1929.

26. Kanthawong S, et al. Antimicrobial and antibiofilm activity of LL-37 and its truncated variants against Burkholderia pseudomallei. Int J Antimicrob Agents. 2012;39(1):39-44.

27. Coyne MJ Jr, Russell KS, Coyle CL, Goldberg JB. The Pseudomonas aeruginosa algC gene encodes phosphoglucomutase, required for the synthesis of a complete lipopolysaccharide core. J Bacteriol. 1994; 176(12):3500-3507.

28. Jenssen H, Hamill P, Hancock RE. Peptide antimicrobial agents. Clin Microbiol Rev. 2006;19(3):491-511.

29. Greenfield NJ. Analysis of the kinetics of folding of proteins and peptides using circular dichroism. Nat Protoc. 2006;1(6):2891-2899.

30. Wang G, Li X, Wang Z. APD2: the updated antimicrobial peptide database and its application in peptide design. Nucleic Acids Res. 2009;37(Database issue):D933-D937.

31. Yeaman MR, Yount NY. Mechanisms of antimicrobial peptide action and resistance. Pharmacol Rev. 2003;55(1):27-55.

32. Xiong YQ, Bayer AS, Yeaman MR. Inhibition of intracellular macromolecular synthesis in Staphylococcus aureus by thrombin-induced platelet microbicidal proteins. J Infect Dis. 2002;185(3):348-356.

33. Spindler EC, Hale JD, Giddings TH Jr, Hancock RE, Gill RT. Deciphering the mode of action of the synthetic antimicrobial peptide Bac8c. Antimicrob Agents Chemother. 2011;55(4):1706-1716.

34. Dathe M, Wieprecht T. Structural features of helical antimicrobial peptides: their potential to modulate activity on model membranes and biological cells. Biochim Biophys Acta. 1999;1462(1-2):71-87.

35. Pathak N, et al. Comparison of the effects of hydrophobicity, amphiphilicity, and alpha-helicity on the activities of antimicrobial peptides. Proteins. 1995;22(2):182-186.

36. Brogden KA. Antimicrobial peptides: pore formers or metabolic inhibitors in bacteria? Nat Rev Microbiol. 2005;3(3):238-250.

37. Hancock RE. Peptide antibiotics. Lancet. 1997; 349(9049):418-422.

38. Wilmes M, Cammue BP, Sahl HG, Thevissen K. Antibiotic activities of host defense peptides: more to it than lipid bilayer perturbation. Nat Prod Rep. 2011;28(8):1350-1358.

39. Breukink E, et al. Use of the cell wall precursor lipid II by a pore-forming peptide antibiotic. Science. 1999;286(5448):2361-2364.

40. Edgerton $M$, et al. Candidacidal activity of salivary histatins. Identification of a histatin 5-binding protein on Candida albicans. J Biol Chem. 1998;
273(32):20438-20447

41. Nielsen SL, Frimodt-Moller N, Kragelund BB, Hansen PR. Structure-activity study of the antibacterial peptide fallaxin. Protein Sci. 2007;16(9):1969-1976.

42. Chia CS, Gong Y, Bowie JH, Zuegg J, Cooper MA. Membrane binding and perturbation studies of the antimicrobial peptides caerin, citropin, and maculatin. Biopolymers. 2011;96(2):147-157.

43. Chen HC, Brown JH, Morell JL, Huang CM. Synthetic magainin analogues with improved antimicrobial activity. FEBS Lett. 1988;236(2):462-466.

44. Krushna Padhi B, Akimenko MA, Ekker M. Independent expansion of the keratin gene family in teleostean fish and mammals: an insight from phylogenetic analysis and radiation hybrid mapping of keratin genes in zebrafish. Gene. 2006;368:37-45.

45. Karantza V. Keratins in health and cancer: more than mere epithelial cell markers. Oncogene. 2011; 30(2):127-138.

46. Moll R, Divo M, Langbein L. The human keratins: biology and pathology. Histochem Cell Biol. 2008;129(6):705-733.

47. Sivamani RK, Garcia MS, Isseroff RR. Wound re-epithelialization: modulating keratinocyte migration in wound healing. Front Biosci. 2007; 12:2849-2868.

48. Molle V, et al. First evidence of the pore-forming properties of a keratin from skin mucus of rainbow trout (Oncorhynchus mykiss, formerly Salmo gairdneri). Biochem J. 2008;411(1):33-40.

49. Vos JB, et al. Transcriptional response of bronchial epithelial cells to Pseudomonas aeruginosa: identification of early mediators of host defense. Physiol Genomics. 2005;21(3):324-336.

50. Qi W, Boyao W. Defense mechanisms of urinary bladder: studies on antimicrobial polypeptides from bladder mucosa. Chin Med SciJ. 1999;14(1):17-22.

51. Kolsch A, Windoffer R, Wurflinger T, Aach T, Leube RE. The keratin-filament cycle of assembly and disassembly. J Cell Sci. 2010;123(pt 13):2266-2272.

52 . McGowan K, Coulombe PA. The wound repair-associated keratins 6,16 , and 17 . Insights into the role of intermediate filaments in specifying keratinocyte cytoarchitecture. Subcell Biochem. 1998;31:173-204.

53. Coulombe PA, Tong X, Mazzalupo S, Wang Z, Wong P. Great promises yet to be fulfilled: defining keratin intermediate filament function in vivo. Eur J Cell Biol. 2004;83(11-12):735-746.

54. Owens DW, Lane EB. Keratin mutations and intestinal pathology. J Pathol. 2004;204(4):377-385.

55. Jaitovich A, et al. Ubiquitin-proteasome-mediated degradation of keratin intermediate filaments in mechanically stimulated A549 cells. J Biol Chem. 2008;283(37):25348-25355.

56. Rogel MR, Jaitovich A, Ridge KM. The role of the ubiquitin proteasome pathway in keratin intermediate filament protein degradation. Proc Am Thorac Soc. 2010;7(1):71-76.

57. Yazaki M, Kashiwagi K, Aritake K, Urade Y, Fujimori K. Rapid degradation of cyclooxygenase-1 and hematopoietic prostaglandin D synthase through ubiquitin-proteasome system in response to intracellular calcium level. Mol Biol Cell. 2012; 23(1):12-21.

58. Ando Y, Miyachi Y, Imamura S, Kannagi R, Murachi T. Purification and characterization of calpains from pig epidermis and their action on epidermal keratin. J Invest Dermatol. 1988;90(1):26-30. 
59. Makowski GS, Ramsby ML. Degradation of cytokeratin intermediate filaments by calcium-activated proteases (calpains) in vitro: implications for formation of Mallory bodies. Res Commun Mol Pathol Pharmacol. 1998;101(3):211-223.

60. Persson H, Kawashima S, Karlsson JO. Immunohistochemical localization of calpains and calpastatin in the rabbit eye. Brain Res. 1993;611(2):272-278.
61. Eng JK, MacCormak AL, Yates JR 3rd. An approach to correlate tandem mass spectral data of peptides with amino acid sequences in a protein database. J Am Soc Mass Spectrom. 1994;5(11):976-989.

62. Tabb DL, McDonald WH, Yates JR 3rd. DTASelect and Contrast: tools for assembling and comparing protein identifications from shotgun proteomics. J Proteome Res. 2002;1(1):21-26.
63. Tam C, et al. 3D quantitative imaging of unprocessed live tissue reveals epithelial defense against bacterial adhesion and subsequent traversal requires MyD88. PLoS One. 2011;6(8):e24008.

64. Rowe PS, Meadow PM. Structure of the core oligosaccharide from the lipopolysaccharide of Pseudomonas aeruginosa PAC1R and its defective mutants. Eur J Biochem. 1983;132(2):329-337. 